\title{
Owning an Older, No-Longer-New, Used Car ${ }^{1}$
}

\author{
Rodney Evans, Independent Scholar, United States of America
}

Email:rod.evans@verizon.net

\begin{abstract}
In his highly insightful and wide-ranging rebuttal article "Doing Phenomenology on the Things," van Manen makes the important claim that "the mission of modern phenomenology transcends foundational and exegetical philosophical theorizing" (2019, p. 3). I take this claim seriously and put forward this article as an exercise in practical lifeworld phenomenological reflection. By lifeworld I refer to the environing world in which we are enmeshed and in which we live and breathe and have our being; it penetrates our awareness of things while at the same time offering the possibility of reprieve from complete enmeshment (submergence) in the form of existential reflection on the things, events, doings, goings-on, etc., that collectively constitute the phenomenological concept of world. By phenomenological reflection, I refer to written analyses (texts) that approach mundane lifeworld phenomena in a manner or style that seeks to show or reveal aspects of the lifeworld that in the ordinary course of everyday life remain hidden from view... aspects of the lifeworld that while they may be glimpsed fleetingly from time to time, remain largely hidden, i.e. in a state of unrealized concealment. The article thus takes seriously the Husserlian call for a return "to the things themselves." And while the ostensible topic is an old (or older) used car, the defacto topic is "us," or perhaps better stated, the actual topic arises at the meeting place where the "us" (as subject) and "an older car" (as object) arrive and conjoin. It is at the place of this meeting between self and world that the phenomenological analysis can begin. The article emphasizes the practical import of this meeting, this engagement - it is not regarded as a matter of purely abstract philosophical theorizing nor as a purely descriptive (empirical) matter, although it is also that in part too.
\end{abstract}

Keywords: phenomenality, phenomenological reflection, doing phenomenology

\footnotetext{
${ }^{1}$ The author wishes to acknowledge the contribution of the organizers, presenters and student co-participants in the 2013 summer course on meaning and method in phenomenological research and writing, held on the campus of The University of Utrecht, The Netherlands. This intensive 2-week course attracted an international gathering of students from various professional disciplines from across North America (Canada and the USA), the UK, Norway, China, The Netherlands, and several eastern European countries. Special thanks are due to the course organizers/presenters for the preparation, pre-preparation and delivery of the 2-week course. In no particular order these include Professor Cathy Adams, University of Alberta, Canada; Professor emeritus, Bas Levering, University of Utrecht; Professor emeritus, Max van Manen, University of Alberta; and Professor Michael van Manen also of the University of Alberta. The seed of an idea for the present paper was planted during the author's participation in this course.
} 
Evans

Phenomenology is driven by wonder, the practice of a pathos. The fascination of the originary sense of meaning: the pathos of returning to the things and on the things.

Max van Manen (2019)

\section{Introduction}

In today's world, could there be anything more mundane, more ordinary, less deserving of time and philosophical attention than an older, no-longer-new, used car? On its face this might seem a rather odd topic for a philosophically based research paper-more appropriate for a do-ityourself YouTube video than an academic philosophy journal. Surely something of greater scholarly moment could be found. But an older, no-longer-new, used car? This sounds like the most barren and fruitless of topics, more a parody than anything approaching a serious scholarly endeavour. Still, philosophy aside, we cannot deny that we live amidst and amongst our cars, are in and out of them countless times each and every day, use them for going here and there, for this or that purpose. Yet unless the car is "ours" it commands relatively little attention. Even then, its sheer omnipresence in our lives means we pay it virtually no heed. Unless and until we encounter a breakdown of some kind - then things change. Then we start to notice. Otherwise, the vast number of cars and vehicles we encounter on the roads each day are met with complete indifference; so long as they follow the accepted "rules of the road" they are simply there. They take up physical space, of course, but occupy no imaginative inner or reflective space. From the perspective of the individual motorist who must share the road with others, we encounter other such vehicles merely as objects with which we must contend, not as objects that hold forth any intrinsic interest or significance for us. "Choose a different topic!" I hear the echo of the teacher's stern admonition. Good advice perhaps. But what if the topic is less the thing chosen than the thing that does the choosing? What if the topic chooses us? What then?

\section{A Brief Excursion into the "What Then?"}

What should we make of the "what then?" Then things begin to change; our view of things begins to shift. Cracks appear in things that were once solid, intact. Old certainties of knowing, of speaking, of thinking become less certain. We glimpse something new, strange. Something unbidden and unforeseen. Heidegger (1994) speaks of a "distress" that accompanies the shift, the cracking open, the opening-up. He asks new and different questions about what he calls the "basic questions" of philosophy; he reaches deep into the question of what it means to "do" philosophy; he touches disdainfully on what he calls the time-honoured, "selected problems" of "logic." The scare-quotes are his. Terra-firma is no longer so firm; there are (and will be) aftershocks. This is the immediate and the longer-term upshot of the "what then?"

\section{Phenomenology as the Practice of Mindful Attentiveness}

At its core, phenomenology is all about paying attention. As we hold things in our phenomenological "gaze" we begin to see different sides of the same thing. Perspectives shift. Things assume a meaning and a significance that had not been there before. Or as van Manen (2018) says, things turn "more enigmatic." Indeed. But an older, no-longer-new, used car? What could be less enigmatic than that? To see the enigmatic quality of the world can be challenging; the given world has its own resistances; it requires, as Heidegger puts it, a certain attitude or 
"disposition" whereby we begin to see that what had heretofore been seen as mundane and commonplace contains within it the seeds of the enigmatic. Can the mundane teach us something? Van Manen makes essentially the same point when he writes that what makes phenomenology "so fascinating" is that "any ordinary experience tends to become quite extraordinary when we lift it up from our daily existence and hold it with our phenomenological gaze" (van Manen, 2018). Heidegger makes a similar point when he says - and here I paraphrase - that in our 'daily doings' we never experience the world's usualness as the usual, precisely because it is "the most usual." For Heidegger the everyday quality of usualness "first erupts" and we come in sight of it only when "the most usual" becomes "the most unusual." Only then, i.e. when things turn enigmatic, do we encounter the usual as the usual. Up to that point the usualness of our world remains concealed, out of sight, hidden from view. Heidegger makes an important point when he says, "the most usual first steps forth separately in its usualness and in its unusualness, such that these then appear [together] precisely as such" (Heidegger, 1994, p. 146). He is saying that "the usual" and "the unusual" (i.e. the enigmatic) emerge together, contemporaneously as it were. This reciprocity, this requirement of each needing and requiring the other is an important phenomenological principle.

In this essay I am going to take a leaf out of Heidegger's rather profound point that for most of us, most of the time, the mundane - what Heidegger refers to as the world's "usualness"- is not experienced as such; it is, so to speak, passed over in its "givenness." Again, the things of our world - older, no-longer-new, used cars for example — are for the most part simply there, and it is precisely this quality of thereness that renders the things of our world largely invisible, transparent to awareness, immune to questioning philosophical or otherwise. What would be the point? What could such questioning yield? And yet Heidegger insists that it is precisely this kind of questioning that must be re-learned, re-discovered. It is the " $r e$ " that is important here. We might call it the deep need we have, to once again learn to pay attention. In this writing I want to practice what it means to "pay attention." In this essay I want to say something about what it could mean to be the owner-driver of an older, no-longer-new, used car or vehicle. I want to practice thinking in its more originary, primordial, phenomenological sense-not as a trick or a gimmick, nor as a mere experiment in thinking, but as something more basic. Thinking as it can be practiced "in and on the things."

\section{Back to the Things Themselves: From Phenomenology in its Classic Philosophic-Transcendental Sense to Phenomenology in its Mundane Lifeworldly Sense}

In taking up the topic of an older, no-longer-new, used car I am going to rely to a great extent on my personal experience of owning a high-mileage sport utility vehicle (SUV). All phenomenological investigations inevitably begin with an element of subjectivity. As van Manen (2018) points out, all experience is first and foremost someone's experience, which is why he says that the starting point is egological: there is an ineluctable element of "mineness" to experience. However, he is careful to point out that personal experience is merely the starting point. In a recent paper, van Manen (2018) emphasizes that what separates phenomenological analyses from, say, psychological analyses is that phenomenology does not address the personal particular or the biographic "but the personal human existential" (van Manen, 2018, emphasis in original), or what he has elsewhere called phenomenality. It is at the point of phenomenality that the "I" drops out. At this point the experience is neither mine nor yours but rather an 
intersubjective or inter-human experience that is equally available to all. And this is because phenomenality attaches to the experiential phenomenon in question rather than to the person doing the experiencing. This is an important point, if for no other reason than that the phenomenality of experience has an intersubjective counterpart while experiences of the personal or biographic kind are almost always idiosyncratic. This is not to diminish the value of the personal, only to say that such analyses lean more psychological than phenomenological. And while I am going to draw upon philosophically based phenomenological concepts for my analysis, I regard this analysis as belonging to the genre of human science research in its lifeworldly sense, rather than an exercise in phenomenological philosophy in its classic (transcendental) sense. It is, in short, an empirical investigation albeit of a philosophical kind. Still, the importance of phenomenology in the classic philosophical (transcendental) sense cannot be overstated, as van Manen (2018) has made abundantly clear. It is this philosophy which must lead the way. And yet for those of us in the lifeworldly professions - teaching, nursing, counselling, administering, midwifery, mental health advising, and so forth - the task is less that of engaging in abstract philosophical theorizing than of re-thinking or re-envisioning various aspects of the practices themselves. This research, then, is a different kind of practice, one that cannot be reduced to the well-known distinction between pure and applied science, or even between pure and applied philosophy — even assuming there could be such a thing. We might do well to attend to Heidegger's distinction between identity and sameness. For while these practices - the philosophically transcendental and the lifeworldly - have much in common, and while there exists much overlap between them, they are not identical. Let us proceed.

\section{Back to Basics: Placing a Porous Boundary Around the Topic}

In this work I want to reflect phenomenologically on what it means - or less definitively, on what it might mean or could mean - to own an older, no-longer-new, used car. The emphasis will be on the owning or the ownership of such a car, but because owning also implies driving I will not ignore the driving aspect. But first I will add a little more clarification on what is meant by an old, or more accurately, an "older" car.

In what sense am I justified in speaking of my 20 -year-old SUV as an "older" car in the title phrase of this piece? Is my old car genuinely "old," or is it simply "no-longer-new"? There is obviously a difference here. In the brief history of automobiles, modern, high-mileage, "older" cars occupy a kind of vehicular no-man's-land. Precisely because they are no longer "new" they lack the discernable quality of "newness" and "innovativeness" that catches the eye and arouses at least a frisson of admiration for the latest, avant-garde, "new arrival." By the same token, today's so-called "older cars" name cars that are not yet truly old, i.e. they have not yet acquired vintage-car status, or the classic "look" of a bygone age that only time and a certain quality of craftsmanship can confer. In this work I am going to accept the verdict that cars that are genuinely old belong to a different time and to a bygone world - think, for example, of the iconic Model-T Ford, or the classic, hand-cranked, 1930's era, British-made, Morris-Eight. My “older" car is not one of these.

So, it is important to clarify that my SUV is by no means "old" in that sense. With its innovative keyless entry system, four-speaker surround sound audio system, and fuel-injected V8 engine, my SUV is hardly "old" in the way we typically think of antique, classic, or vintage cars. But if it is not old in that sense, it is certainly not new. Parked on my driveway, it reveals the scrapes and scratches, dints and dents from casual encounters with parking lot shopping carts, 
carelessly opened car doors, inconveniently located concrete bollards, mysteriously situated roadside curbs - not to mention the day-to-day deterioration from weather and the passage of time. From time to time I flirt with the possibility of a new paint job, but at this point, pride of ownership has given way to a more pragmatic concern for utility. I want my SUV to run wellno more, no less. And yet as a socially conscious driver, I am also aware that in the modern era of flex-fuel, hybrid, and electric cars, my SUV loudly proclaims its politically incorrect status. Even a short drive across town reminds me that I drive an uneconomical vehicle. But there it sits, parked on my driveway - seldom inside my garage, mainly because I like the ease and convenience of being able to climb inside and drive away. As an object in the urban landscape it is notable only in terms of its ordinary everydayness, indistinguishable from many of the same or similar vehicles we see on the roads each day. To the casual observer who happens by, my highmileage SUV elicits barely a second glance, arousing neither curiosity nor concern - and certainly not envy.

Still I cannot let it go. Why? Mainly, I think, because it is so familiar and so well known to me. But today I have errands to run and things to attend to. I grab my car keys from their customary hook and head outdoors. On the driveway, my fingers punch in the entry code on the digital keypad, I open the door and climb inside. Once inside, the driver's seat with its tilt control and power-assisted adjustments holds me comfortably in place at the right height and right degree of uprightness for a clear and unimpeded view of the driving terrain - the road ahead, the road behind and to the sides. The driving controls - floor pedals, steering wheel, and columnmounted gear shift - are conveniently located, ready-to-hand, so that without taking my eyes off the road I can control my SUV by touch and feel alone. This frees me to concentrate on the external driving environment - an important consideration in today's rather intense driving conditions and the current state of driving technology. Of course, we can speculate whether all this elaborate preparation will become obsolete with the advent of driverless cars of the future, but for now the need to pay close attention to the road before me-especially in view of the rampant inattentiveness of many modern drivers-is obvious.

Without looking, I reach for my seat belt behind me and pull it across my body, listening for the tell-tale "click" that tells me the belt is properly secured. I am now prepared and wellpositioned for my drive. And thanks to my SUV's higher-than-normal centre of gravity, I have an elevated view of the road ahead and the terrain surrounding me. This elevated viewpoint is an advantage when crawling along behind slow moving traffic or navigating through maze-like construction zones; it allows me to see the extent of backed-up traffic and take evasive action when needed.

As someone who enjoys driving, I like the convenience that comes with having quick and easy access to the modern dashboard controls that make today's driving a more rewarding and enjoyable experience. These modern accessories - sophisticated sound systems, on-board navigational devices, rearview cameras, cruise control, and so forth — provide today's motorist with a level of driving convenience that extends far beyond the primary controls that give the driver his basic control over his vehicle - the floor-mounted accelerator, brakes (foot brake and hand brake), gear shifting mechanism, and power-assisted steering. Still, this mechanical control is no guarantee of a completely safe or incident-free drive. In addition to the mechanical aspects of driving there is the ever-present human factor which can never be discounted.

One of the things that makes my older model SUV such a pleasure to drive is that, once inside, there is no fumbling — with the key, the ignition, the gearshift, the pedals, the rear-view mirrors. Quite different from the new car or rental vehicle where everything is strange-where 
the driver's seat needs adjusting to accommodate for the driver's leg length and distance to the pedals, where the rear-view mirrors need adjusting to align with the driver's height and eye position, and where the new and unfamiliar driver must undergo a voyage of discovery to locate the whereabouts of the mysteriously hidden controls. Now, as I grasp the leather-wrapped steering wheel in one hand and slip the key into the ignition with the other-a quick turn of the key - my V-8 engine springs to life. As ignition takes hold, the engine begins its steady rhythmic purring. One feels the vibrations as a kind of external, mechanical pulse. My old vehicle has come "alive" and is once again ready to depart. Pressing down hard against the brake pedal, I grasp the gear lever and urge it into the drive position. Now, as I slip into first gear and add a little gas, I am ready to begin my journey. A quick check of the dashboard gauges assures me that all the important mechanical functions (oil pressure, engine temperature, battery charging, etc.) are normal and working well. However, a quick glance at the fuel gauge informs me that the gas tank is registering close to empty. I make a mental note that I will need to fill up the fuel tank at the nearest gas station before travelling too far afield.

I am now ready to ease into the street and begin my journey. Having driven for many years I do not feel nervous about driving or encountering other motorists along the roadway. This differs from the experience of novice drivers or those learning to drive for the first time. In their first foray into busy streets, first-time drivers encounter other cars with varying degrees of apprehensiveness. As a beginning driver one is tempted to slow down or at least pull over towards the side of the road to allow the approaching driver a wide margin to pass by. One does not yet know enough about one's driving capabilities, the rules of the road, the subtleties of driving etiquette, or the capabilities of the vehicle one is driving. Nor does one know the precise motivations of other drivers. Are they passive, polite, or aggressive drivers? What are their reflex abilities or their skill-levels behind the wheel? Are they beginner-drivers too? While the experienced driver pays little to no attention to such matters, for the novice driver such factors can be worrisome.

Today my SUV is driving nicely with no obvious mechanical problems, heavy traffic, or unanticipated construction zones to interfere with the pleasure of my drive. I take this as a good sign, that despite its age, the mechanical aspects of my car's internal-combustion engine are working well, transferring the auto-motive power from the engine to the rear wheels. Halfway to my destination I notice that my car has developed a slight tendency to drift to the right when driving down a straight stretch of highway. I suspect a wheel alignment problem. This is moderately worrying as I know from prior experience that if this problem is not corrected it will only get worse with time. But for the moment I am not overly concerned. I make a mental note to have the problem checked at its next regularly scheduled service.

My car is more than a means of personal transportation. Its large interior cargo space is what enables me to transport all manner of stuff - groceries from the store, building supplies, landscape materials for work projects large and small. For this its age and its well-worn status are something of a blessing - no longer do I feel the need to park in remote corners of supermarket parking lots fearful of the carelessness of other drivers; I no longer fret over nicks and scrapes, a door ding here or dented fender there. At this point I am no longer obsessively concerned with maintaining my vehicle in a state of unblemished newness; this frees me to get on with the mundane tasks of ordinary everyday life in a more sustainable, down-to-earth, pragmatic fashion. 


\section{On the Existential Freedom Factor Involved in Owning an Older, No-Longer-New, Used Car}

At this point we need to take a short detour to remind ourselves of our task here. We are trying to draw out phenomenality. In the case of this research this means the phenomenality that inheres in the experience of owning an older, no-longer-new, used car as opposed, let us say, to a brand-new car fresh from the automobile dealer's showroom. Methodologically speaking, we are trying to reach phenomenality via descriptive-interpretive, first-person accounts of what it is like to be the owner-driver of a specific kind of older vehicle. We are trying to speak in existential terms about what it might mean to be the owner-driver of an older, no-longer-new, used car or SUV. And we are starting with the unavoidable assumption (unavoidable in the sense that we have to start from somewhere, we cannot start from nowhere) that one experiences ownership of such a vehicle in some rather specific ways - in short that it means something. We are trying to say in whatever way we can, in whichever way we can, what that something is. This an exercise in practical (not merely theoretical) ontology.

Let us examine for a moment what, for want of a better term, we may call the existential "freedom factor" that inheres in the ownership of an older, no-longer-new, used car. Sartre once said, "The Americans believe they are free in their cars." Coming from the man who once famously said "[m]an is condemned to freedom", the sarcasm is palpable. And yet for many of us in today's world, powerful new cars or trucks are indeed thought of as the epitome of undiluted personal freedom. We admire their gleaming newness and the power they confer. Car manufacturers extol the beauty and the freedom of the "open road," the freedom to be oneself, to choose one's destination, free to travel and explore - north, south, east, or west on a whim and a full tank of gas. What could be more freeing than that? But thought of ... is not the same as experienced as... One is a post-hoc, after-the-fact, rationalized cognition. We think that ownership of a powerful new car or truck equals freedom. Or we might argue-perhaps correctly - that we have been persuaded to think that ownership of a powerful new car equals freedom. Either way we are speaking of an act of cognition. But phenomenology in its original sense wants to seize on what exists prior to all rationalized cognitions. It wants to seize on the inceptual moment of the way we actually experience the world, of the way the world becomes present to us in pre-reflective, pre-conceptual, pre-rationalized experience. This is one reason why descriptively based, phenomenological reflections are often experienced as painfully and nakedly honest. At its core, experience does not lie, does not deceive-it cannot be otherwise than what it is. It is not a type of representational thinking because it is not a type of thinking at all. Of course, as van Manen (2019) points out, there is always the possibility that we may fumble or fall short in our efforts to capture the precise nature of the experience, we may misinterpret or fail to find the right words with which to describe the experience in question, but the experience remains the experience that it is. It is not anything that can be prepared for because it is not anything that we are in charge of. All we can say is that it occurs, it happens. Heidegger speaks of a suffering, of the way we might experience (suffer) a "blow" of some kind. The "as" in the "experienced as" is what befalls us when we are looking the other way, when we are not paying attention; it is what happens above and beyond all wanting and willing, above and beyond all human planning and contriving. Perhaps this is the best we can say-experience as something suffered; a blow from beyond; an involuntary something that is nevertheless available to us in an act of reflective appropriation - as van Manen (2019) points out in his introductory epigraph from the text of Gallagher and Zahavi (2008). 
But back to the lifeworld from which we have once again been temporarily distracted. We want to see in what way ownership of an older, no-longer-new, used car or truck is experienced, not in a final or definitive way certainly, but in a way that is broadly recognizable as belonging to the phenomenon in question. One way to clarify this or any other experience is by asking about its obverse; that is, by returning or referring to the experience of owning and driving a brand-new vehicle straight from the dealer's showroom. This is what phenomenological philosophers refer to as "the real or imaginary variation of the given" as one method for clarifying "the intentional meaning-structure of a [given] phenomenon" (see van Manen, 2019, p. 7).

\section{Disclosing the intentional meaning-structure of owning an older, no-longer-new, used car by beginning with the experience of becoming the owner of a brand-new car fresh from the automobile showroom}

Despite efforts by automobile manufacturers to convince us otherwise, it is entirely possible that becoming the owner of a brand-new car or truck is in many ways an exercise in the practice of unfreedom. How can such a statement be justified? As it stands it is merely an unfounded assertion, of little value unless it can be shown to possess an element of hidden truthfulness. Again, I am acting on the assumption that fine-grained, first-person, experiential descriptions of the lifeworld — real or imaginary — can be phenomenologically revealing.

The nervousness often experienced by new car buyers is well known to many of us. As I drive my shiny new car out from the dealer's showroom, I am wrapped up in the excitement of owning and driving a powerful new vehicle. Due to its newness and unfamiliarity I drive cautiously, leaving a safe stopping distance between my new automobile and the traffic up ahead. I grip the steering wheel with both hands as I concentrate on my driving, staying well within posted speed limits and paying close attention to the ever-changing, moment-by-moment, road situation I am part of. I keep a safe distance behind the car in front of me in case its driver brakes suddenly. I find myself keeping a watchful eye in the rearview mirror on the traffic approaching from behind; I am uneasy when the car behind me follows too closely, tailgating me. Is this driver concentrating on his driving? Is he trying to intimidate me? If I stop quickly, will he be able to stop in time? As the traffic-lights ahead turn from green to red, I bring my vehicle to a carefully measured stop well behind the car in front. I am not yet ready to take any chances. Along the way, I am on the lookout for signs of negligent or distracted drivers. Of course, such an overly vigilant style of driving does not last forever, and as I gain familiarity with my new vehicle, I make the transition to a less defensive driving style - not sloppy or careless or egocentric by any means, but certainly more relaxed and much less hyper-defensive. While this overly cautious style of driving is not the same for every driver, this experience will be familiar to many owner-drivers of new or almost new cars and trucks. At this point we need to flesh out in a little more detail our earlier assertion that new cars or trucks are, or can be, experienced as a source of un-freedom. To do so we will draw on a simplified version of the socalled eidetic reduction - variously described in the phenomenological literature as "the imaginative variation of the given" (van Manen 2019), or as simply "imaginary variation" (Morley, 2010) — as our way of shedding light on the above mentioned assertion.

As a proud owner of a gleaming new car or truck we examine its condition daily, perhaps after every drive. We check for scratches and scrapes, clean off windows and paintwork, polish 
up the chrome-work and hub caps, inspecting our new acquisition with meticulous care and attention. We are in thrall to its gleaming newness. As conscientious owner-drivers, we take careful note of the dates and distances between scheduled maintenance, change engine oil precisely on schedule, take our new possession to the local carwash to maintain its polished gleam, and park it under cover at the first sign of rain. Perhaps we should not be too surprised at the care and attention lavished on our new possession - in the modern world new vehicles are coveted possessions. When driving out of town we take detours to avoid driving on rough or unpaved roads; in town we make an effort to avoid construction zones and seek out remote corners of supermarket parking lots to avoid contact with other, less careful drivers. We pamper our new acquisition and drive it with 'kid gloves'. Phenomenologically we could ask: What is it that speaks in such attentiveness? Who owns who? Do we own our new car or does our new car own us? These are not intended as purely rhetorical questions.

\section{Searching for Experiential Essence as the Essence of Phenomenality}

At this point a question arises: How is all this protecting and pampering of our new car experienced? This is where a certain amount of interpretive work enters the picture. At one extreme the obsessive concern just described could be experienced as something willingly and even eagerly embraced as the new car owner falls under the sway of what we may provisionally term new car syndrome, and the quasi-eroticized infatuation that follows in its wake. But it is also possible that all the lavishing and pampering and protecting could be experienced not as something light at all, but as something heavy like a weight or a burden which we are obliged to carry. Not a duty exactly, but certainly an obligation. This, after all, is what new car owners are supposed to do. Here we encounter a fork in the road as it pertains to the phenomenological concept of phenomenality. Another question arises: Does phenomenality refer to the qualitative content of experience as some phenomenologists appear to suggest, or does it refer, as van Manen (2019) proposes, to the "phenomenological meaning structures that inhere in prereflective or pre-predicative experience"? This is no small distinction. If it is the qualitative content of [an] experience, then such "content" will likely vary according to whoever is undergoing the experience as outlined above. Here, we cannot assume a univocal response to experience, to what strikes us, but must be prepared for a multiplicity. Van Manen alludes to this possibility when, in his recent, wide-ranging rebuttal article "Doing Phenomenology on the Things" he cites the comments of Claude Romano to the effect that "our conceptual and linguistic schemes ... can influence the manner in which we experience the world, ourselves, and others" (van Manen, 2019, p. 10). If, on the other hand, phenomenality refers to the "inherent meaning structures" then something approaching a community of experience can be inferred. When Heidegger in his descriptive account of 'being bored' describes the impatient pacing up and down on the railway station platform for a train that never comes, the mind-numbing reading and re-reading of the railway station timetable in a futile attempt to kill time, we recognize this as a mind-numbing, soul-crushing moment of what it means to be bored. In his descriptive account we come face-to-face with what it is like to be bored. In other words, Heidegger is giving us an instance of what it is like to be bored, or if we prefer, of the phenomenality of boredom. This is not the same as providing an abstract definition (of boredom) or of treating boredom as a concept. We might say that Heidegger provides us with an instance of what we can call the beingness of boredom in his otherwise ontic account of waiting at a railway station for a train that never comes. In his compelling account, Heidegger is reflectively recollecting the inherent 
Evans

meaning structure(s) that inhere in the pre-reflective moment of experience, in this case, the experience of being bored. He is not describing the qualitative content of the experience of boredom itself. But once again the lifeworld beckons - we have no desire to linger in the abstract world of theory any longer than strictly necessary. We linger only so long as needed to establish a pathway back to the lifeworld.

\section{Breaking the Spell: New Car Ownership and the Issue of Psychological Unsustainability}

In today's world, the issue of sustainability is clearly important. Owning a new car is a case in point. As we drive the new vehicle home from the new car showroom we can ask whether all the attention lavished on our new acquisition is sustainable, or whether it is a metaphor for unsustainability — a symptom of a quasi-psychological disposition we have previously designated as new car syndrome. To repeat: I am using this term as a way of referring to the infatuation new car owners often display towards their new possession. But with my older, high-mileage SUV this is emphatically not the case. Here things are noticeably different.

As the owner-driver of my well-travelled, high-mileage SUV that outwardly at least has seen better days, I no longer drive with the hyper-vigilance and hyper-defensiveness that accompanies ownership of new or almost new cars and trucks. At the same time, a freeing experience goes hand in hand with ownership of an older SUV, a freeing that can best be described as an unburdening, whereby we mean to refer to the fact that everyday life can now be lived in more pragmatic, down-to-earth, sustainable terms. This is not just the more commonly addressed notion of material sustainability, it is also and more poignantly a type of psychological sustainability, whereby we mean to refer to a type of dispositional coming-toterms with certain irreversible, lifeworldly realities, e.g. the fading paintwork, the emerging rust spots, the mysterious sounds coming from under the hood - that accompany ownership of older, no-longer-new, used cars or trucks. This psychological sustainability can be experienced as an unburdening, or as a letting-go. Heidegger refers to it (albeit in a different context) as a type of "releasement." Of what? In our case, a 'releasement' from a certain over-infatuation with newness and a hyper-attentiveness that accompanies ownership of new, or almost new, cars and trucks. With the loss of newness the spell is broken. I am no longer in the grip of something I do not fully understand. I am no longer in thrall to newness in its various permutations and appearances.

\section{On Winning Back or First Developing the Hidden Power of Naming the Essential}

In his text "Basic Questions of Philosophy" Heidegger speaks of the need "to win back, or, perhaps, first develop, for our language a hidden power of naming the essential" (Heidegger, 1994, p. 131). This "need", as Heidegger calls it, is made difficult by dint of the fact that modern metaphysics posits that only that which is "present at hand", i.e. only that which affirmatively exists, "counts as a being." (We should note in passing that Heidegger takes pains to deconstruct this metaphysical legacy.) So, we can ask: What is essential in our thinking about owning an older, no-longer-new, used car? How (i.e. in what way or in what manner) does ownership of this kind of older vehicle become experientially known to us? 
It is possible and perhaps even likely that we see it first of all in terms of what it lacksand what it lacks most essentially is "newness." But here we must be cautious, for it is not "newness" that is most essential, for "newness" is what my old car lacks, what it has lost, what it no longer "has." My old car now stands before me in a deficit condition-it no longer has what it once had, "newness." So, what is first of all present, and experienced as such, is a lack, a loss, an absence - of what once was present, my old car's newness. What is most obvious and what comes immediately to the experiential forefront is what my old car does not have, and what it does not have is "newness." But this "not," Heidegger insists, is not "nothing," nor should it be seen as an "affliction," nor in any way "lamentable" and certainly not negative. This is not the source of real need as Heidegger sees it. In a complex but highly important turn of thought Heidegger says that this "no" and this "not" is not "nothingness" but, in fact, "is precisely its opposite." The opposite of nothingness is somethingness. He writes, "It never enters the field of view of our calculating reason that a no and a not may arise out of a surplus or abundance, may be the highest gift, and as this not and no may infinitely, i.e., essentially, surpass every ordinary yes" (Heidegger, 1994, p. 132, emphasis added). So we can ask: What then is this "highest gift" that this "no" and this "not," i.e. this "loss" (of newness) gives me? In a word, freedom-or as I would prefer to phrase it, the freeing of myself from myself. I am no longer in thrall to newness. The spell has broken. In a curious reversal, my old car's "loss" or "lack" (of newness) offers itself, in Heidegger's words, as its "highest" gift. It is what has most value. "Not every negation is negative in a depreciatory sense" says Heidegger (1994, p. 131). Do we sense a truth here? With the loss of newness I am released to encounter the world in more down-to-earth, sustainable, pragmatic terms. This is of the essence of freedom-which is also at the same time the essence of truth. This is what Heidegger means when he speaks of "winning back" or "first developing" a hidden power "of naming the essential." But back to my old car. Let us see how this "releasement," this "letting-go" might cash out in more concrete, practical, existential terms. In the words of a popular country-song, we need to get back "on the road again."

\section{On the Road Again: The Loss or Lack of Newness as the Gift That My Older, No-Longer-New Car Gives Me}

Sitting comfortably in the driver's seat I am now ready to set about the tasks I have set for myself. I check my seat belt and make small adjustments to the driver's seat to make sure it is properly aligned with my leg length, distance from the controls, steering wheel, etc. I check to see if I have a clear and unobstructed view to the front, to the sides, and of the road behind me via the rearview mirror. The importance of having a clear field of vision cannot be emphasized enough in today's driving conditions where the ability to see potential hazards looming on the horizon of one's awareness can mean the difference between disaster and arriving safely at one's destination.

My "to-do" list includes a trip to the supermarket for groceries and to the hardware store for lumber to repair a section of fence blown down in a recent storm. This is where the extralarge carrying capacity of my SUV comes in handy, but it is also where I find myself conflicted in my urge to trade in my bulky and decidedly non-economic SUV for a more fuel-efficient car with a smaller carbon footprint. I am conflicted because I am by no means insensitive to the arguments put forth by environmentalists and others on behalf of smaller, less polluting vehicles. Still, I rationalize my choice with the thought that my SUV is more than a means of personal transportation, it is what enables me to transport groceries from the supermarket, building 
supplies from the hardware store, landscape materials from the local nursery for work on projects large and small. My large-capacity SUV is what enables me to accomplish the mundane tasks associated with modern living with relative ease and convenience. It is for this reason that I convince myself that I "need" to hold on to my old truck for now.

Starting my car in preparation for the day's outing is a simple and straightforward process - something I do not have to think about. With all eight cylinders firing smoothly I am ready for my drive. Pressing down hard against the brake pedal I grip the column mounted gear lever and urge it into the drive position. I feel a slight tug on the drive shaft as the transmission engages, which tells me that the (auto) motive power of the engine is being transferred to the rear wheels. I release the pressure on the foot brake and reverse my truck out into the street to begin my journey. One reason I am looking forward to my morning drive is because it will allow me a few minutes to myself. I am looking forward to a few moments of solitude to enjoy the drive and think of nothing in particular. I am now ready to embark on the tasks I have set for myself.

Today my drive takes me along pleasant, tree-lined streets to the main intersection where I instinctively turn left to head to the supermarket. The drive is entirely routine as it is a route I have travelled many times before. Along the drive I lower the windows to take advantage of the mild temperatures and to enjoy the breeze that enters and exits through the open windows. I prefer driving with the widows rolled down as this allows me to hear and see more of the world around me-I am no longer a self-contained monad sealed off inside a metal container indifferent to the world I am passing through. Passing the school playground, I hear the shouted outbursts of children at play; on the street I hear car horns, revving engines, squealing brakes, wailing sirens - all of which have meaning and significance for me. All around me are the sights and sounds of a busy, noisy, working world. I am part of this world and this world is part of me. This makes my drive qualitatively different from the phantom drivers of fast-moving, late-model, black sedans, whose rolled-up tinted windows seal off their occupants from a world they pass through but do not care to know.

Sooner than expected I arrive at the supermarket and pull into the parking lot. It is strange in a way that I have very little recollection of my drive. I do not remember following directions, driving this way or that, of turning right at this corner or left at that one. I am aware, of course, that I did drive - that much is obvious. Here I am at the supermarket! But the journey itself was uneventful, my thoughts were elsewhere. Throughout the drive my car seemed to have a mind of its own and to steer itself to its destination. This is not a unique phenomenon. Other drivers have had the same or similar sense of dislocation and been taken aback to find themselves arriving at one place when their intended destination was elsewhere. It seems we might be justified in raising what at first glance might seem a rather fanciful question: Who or what did the driving? Did I drive the car or did the car drive me? Where is the dividing line between car-and-driver, between driver-and-car? But these are philosophical questions which must be put on hold; for now, I must attend to the mundane tasks before me and get back to my shopping expedition.

I arrive at the supermarket ready to shop for groceries. I pull into the parking lot and thanks to the extra height and ground-clearance of my SUV I easily scan the area for a suitable parking spot. As I approach the coveted parking spot, I judge that the space is large enough for me to park my over-size SUV. This is the beauty of owning an older vehicle I have driven for many years - my vehicle's size, turning radius, and space requirements are all things I know about from experience. Navigating carefully, I approach the vacant parking spot and ease into the available space. As I squeeze out of the driver's side door, I find myself a little too close to the cars parked on either side of me. Is this a safe place to park? But this is not a question I spend too 
much time on. I no longer fret over the possibility that a carelessly opened car door will make much difference.

It is not that I am neglectful of my SUV. I still take time to check fluid levels, maintain correct tire pressure, change oil and air filters at more-or-less regular intervals. It is important that my SUV remain in mechanically good shape as this is my vehicle, my mode of transport and solver of many of life's mundane, day-to-day problems. But I am no longer fastidious. If a rattle or squeak develops, if a non-essential light goes blank, if a crack or chip appears in the windshield, or if the "check engine" light goes on, I no longer rush to the dealership to have it repaired or replaced. At this moment I recognize an element of imperfection as entirely normal, an integral and perhaps even necessary part of life, not just unavoidable but also oddly desirable - mainly for what it allows me to renounce. And what it allows me to renounce is the never-ending quest for perfection that is the constant companion of our culturally determined lifestyle. There is a time to recognize the inevitability of things. We cannot blink the fact that over time things wear down and, in the end, wear out.

Such reflections raise some of the same questions raised at the beginning of this piece. Is my "old" car truly "old" or is it simply "no-longer-new?" Is my SUV just another high-mileage "used" car like so many of the same or similar vehicles we see on the road today? What makes an "old" car truly old? While its dents and scratches and rapidly fading paintwork make it seem old, is it really?

\section{Daytime Driving and Driving in the Dark as Perceptually Different Modes of Driving}

For the human driver and their passengers, it is generally recognized that daytime and nighttime driving are entirely different modalities of driving. During daylight hours, driving is a relaxed and relaxing, relatively stress-free activity most of the time. There are exceptions, of course. Driving in heavy rush hour traffic is undoubtedly taxing, driving in adverse weather conditions can also be stressful and requires a careful eye on road conditions, distance from other drivers, and so forth. But for many drivers, driving has become so relatively effortless and so second-nature that it is a mostly stress-free activity. For long-time owner-drivers, the modern, well-equipped automobile has become a second skin that we slip into and out of with barely a moment's thought or hesitation. Daytime driving is made easier in virtue of the fact that in the light of day the things of our world assume their natural colours, their normal proportions, their ordinary properties - physicality and spatiality are not mysterious; they are knowable and calculable in advance. In daytime driving things can be foreseen, but this is not the case at night.

At night, everything changes. In the enveloping darkness, my vision narrows down from the broad, nearly limitless horizons of daytime driving, to the small patch of road illuminated by my car's headlights. The direction of my gaze is forward, straight ahead. I am no longer the onehand-on-the-wheel, visually distracted driver I can be in the daytime. At night, I grip the wheel firmly in both hands and do not take my eyes off the road ahead. I do not allow my thoughts to wander. I resist the urge to tune in to different radio stations or adjust the heating/cooling controls inside the cabin. I need both hands on the wheel to avoid drifting. I decline conversation with my fellow travelers and answer only in monosyllables as my full attention is needed on the road ahead. Nighttime driving elicits a hyper-alertness and a heightened sensitivity to the basics of driving - staying strictly within the confines of one's lane, for example - as out of the darkness a car or cyclist can emerge to which we are slow to respond. Reaction times are often 
slower at night. Perception undergoes a sea-change. There is a felt-need for extra vigilance at night as a wrong move can spell disaster.

But as the miles roll by, I start to relax. I allow myself a quick glance down at the illuminated dashboard which tells me that all is functioning as it should. I have no immediate or pressing concerns. But tonight I am driving through an unfamiliar part of the countryside and there is always an unvoiced level of apprehensiveness associated with the dark. I try to squelch the ever-present awareness of the possibility of breakdown but only partly succeed. What if my aging alternator finally gives out? What about the annoying squeal of the timing belt that seems to be getting louder by the mile and that despite my better judgment I have put off having inspected for months? Is this the night when one or both could fail? What would qualify as a minor inconvenience in the daytime could be catastrophic at night.

But so far, so good. As my confidence builds, I allow myself the luxury of tuning-in to soft, night-time music from my favorite radio station. I keep the volume low. Perhaps I steal a look at my fellow passengers who have nodded off to sleep. In these moments I feel the weight of responsibility that falls on my shoulders for the safe arrival (or return) of my SUV and its occupants.

\section{On the Still Unanswered Question Regarding the Metaphysical Dividing Line Between Car-and-Driver, Between Driver-and-Car}

We begin once again with a relatively simple, straightforward question: How do drivers experience the bodily act of driving? And relatedly, how do drivers experience the relation between themselves and their "instrument?" We begin by examining this question from what seems like the obvious place to start, namely, from the standpoint of the natural attitude.

From the standpoint of the natural attitude our general perception and associated judgment of things is well established: Here is the car parked at the stop sign, and inside the car is the driver sitting behind the wheel steering the car to its destination. What could be more straightforward than that? We are speaking of two entities here: the car on the one hand and its driver on the other. Boundaries are clearly drawn. A clear and distinct metaphysical dividing line separates the two entities. We are in the presence of the fundamental requirements of logic. Why confuse something clear and simple with a question that only serves to blur distinctions that a moment earlier were seemingly beyond dispute? But as anyone who has ever driven a car for any appreciable length of time knows, this is not the entire picture. Perhaps it is not the picture at all.

We are asking about the dividing line. Lines divide, separate, keep apart. Hyphens (very short lines) do the opposite. At the philosophical level our metaphysics is very good at drawing lines that divide. Logic (especially in the form of mathematics) would be inconceivable without them. But here we are talking about the dividing line between car-and-driver, driver-and-car and the interrelations that can and must exist between them. Rather than accept the metaphysical verdict, we wish to ask about the experiential dimension. We want to know something about the way good drivers - one is tempted to say experienced drivers - experience driving 'behind the wheel' as we sometimes like to say.

As others have suggested, the driver does not steer their car along the roadway or around the bend. The problem with this way of speaking is that, as van Lennep (1969/1987) says, it suggests that "the driver stands outside his car and manipulates his car as an object in the midst of other objects" (van Lennep, 1969/1987, p. 221). When we phrase it this way it implies that the relationship between the driver and his car is primarily mechanical, instrumental, or perhaps we 
should say, mechanical-instrumental. Yet sitting in the driver's seat and grasping the wheel with both hands there is nothing - neither a conscious act nor certainly an unconscious act - that could merit the name of steering in its usual sense. Steering (as a subset of driving) is an organic act. As the driver of my car I am no more self-consciously - or for that matter, un-selfconsciously - concerned with steering any more than the boy on his bicycle is self-consciously (or un-self-consciously) concerned with balancing. Balancing and steering are things that happen outside of, or beyond our self-conscious awareness of things. Lexically speaking, steering is just convenient shorthand for what takes us over once we 'take the wheel.' Not, as we sometimes like to say, 'in a manner of speaking', but actually — which is to say, really, the wheel takes us over. In the same way that balancing (a bike) takes us over once we hold the handlebars, pedal hard, and go. Common parlance is instructive here: when out for a bicycle ride, we say we are riding our bike, we never say we are balancing our bike. Balancing is already part of the embodied act of riding. The same can be said regarding talk of steering one's bike-a term cyclists hardly ever use. For the cyclist, everything hinges on the "riding." For the automobile driver, everything hinges on the "driving." Let us look at this driving in a little more detail.

Driving my car is a seamless act in which the "I" (the body, the self) responds to intentions, in this case to my intention to arrive at the library or the post office or the craft beer store, for example. Of course, there are exceptions. In emergency situations - when we are ripped out of our everyday awareness of things, what we might call our everyday somnambulism - we become instantly more self-conscious about driving, about the totality of circumstances in which we find ourselves, about steering our way around this or that obstacle. We naturally want to avoid whatever disaster may be looming. But under normal, i.e. nonemergency conditions, talk of steering is mostly, if not entirely, superfluous; it is to make selfconscious (i.e. to objectify) what is experienced and performed entirely un-self-consciously, i.e. reflexively - but that may also be too active and psychologized a term. When driving, my body grips the wheel with both hands and without conscious awareness turns the wheel this way and that. My hands literally have a mind of their own. Psychology knows this as an involuntary response mechanism, but such conceptual and conceptualizing language numbs our awareness of the problem we are attempting to grasp in its experiential fullness. Even when we examine the problem physiologically and readily admit that my limbs (arms, wrists, hands) are mechanically moving the steering wheel this way and that, altering the moment-to-moment direction of my travel, at the experiential level there is no physical or psychological awareness that I am steering. The steering wheel—often abbreviated to simply "the wheel" — gives us a clue as to the invisibility of the act we call "steering." But what I do unquestionably have, as driver, are intentions - concrete intentions, e.g. to go to the library, to visit an old friend, to pick up groceries at the supermarket, to go for a pleasant weekend drive, and so forth - and what my body (my "I") responds to are my intentions. What is called steering is better described as an embodied response to intentions; it is inextricably wrapped up in the totality of the act we call driving.

Driving is a complicated and at the same time not a complicated process. It is at once conceptually complicated but at the practical (operational) level not at all complicated. For those who have driven for any length of time it is an easy matter — as simple (almost) as walking. As mentioned earlier, we slip in and out of our cars as if they were a second skin - without hesitation. 
Evans

\section{Developing an Ineffable "Feel" for the "Road" as the Essence of Good Driving}

Good drivers who know their vehicle have a certain feel for the road, for other cars and drivers, for what is going on around them, for what has not-yet-happened but for what in-alllikelihood is about to happen; they develop an intuitive feel for the road and the possibilities it allows and disavows. This "feel" naturally exceeds all rules and legal requirements of and for good driving. Good drivers have a "feel" for felt-time and space and their interactivity, for what can be done - and equally importantly, what cannot be done - under certain driving conditions. One is tempted to refer to this "feel" as a type of instinct that good drivers possess, but to refer to it as an instinctual response is to invoke biological (i.e. naturalistic) explanations that are out of place in a human-science, phenomenological inquiry. Rather, the "feel" that good drivers acquire in the act of driving is a type of perceptual learning built up incrementally such that one knows from the ongoing practical experience of driving what can and cannot be accomplished in certain circumstances. In this regard van Lennep (1969/1987) reminds us that our perception is always a "pragmatic perception," which is to say we always first see how a situation is "for us" (van Lennep, 1969/1987, p. 221). Perception, we can say, is never devoid of evaluative content; there is always an in-built element of judging (of judgment) involved in every act of perceiving. Perception is never an empty perception. But let us get back to the dividing line between carand-driver, between driver-and-car, from which we have once again been temporarily distracted. This is an important issue. We want to see in what way this assumed metaphysical separation is in accordance (or not) with our actual experience (of driving). We want to see the praxis.

\section{Driving as a Form of Bodily Praxis: 'Taking the Wheel' as the Point at Which the Car Becomes an Extension or Prolongation of the Body of the Driver}

What then is our actual experience of driving? In his classic phenomenological analysis of the psychology of driving, psychologist D.J. van Lennep provides a detailed description of the way good drivers, i.e. experienced drivers, experience the act of driving when it is done responsibly, i.e. according to the rules of the road. The strength of van Lennep's account lies in the fact that he does not provide his readers with a mere 'executive summary' of how the act of driving is experienced; rather, he shows, step-by-step, experiential-detail-by-experiential-detail, what this experience is (not even what this experience is like) at the concrete level. I will quote from van Lennep's account at some length in part to show his "research technique" and how this technique is far from anything resembling a technical skill — and how, as phenomenologist, he begins by deconstructing the standard behaviorist theory of driving that inhabits the taken-forgranted world of the natural attitude. He begins by examining the metaphysical dividing linenot so much as a matter of philosophy but rather as an existential (i.e. phenomenological) issue-between car-and-driver, driver-and-car beginning with the previously discussed issue of steering:

... the driver does not steer his car through the traffic situation. This mode of expression would give us the impression that the driver, as it were, stands outside his car and manipulates his car as an object in the midst of other objects. The good driver forms a unity with his car, that is to say his car becomes part of his 
body. The peculiar aspect of an instrument is that man uses it as an extension of his body. One could say that when we draw a line in the sand with the end of a stick, our touch has been extended to the end of the stick. The driver is as wide as his car. He does not "measure" whether or not he can pass through a space, but "feels" it after a while. But he feels it only insofar and for as long as he sits behind the wheel. Whoever sits beside the driver experiences all the misery of socalled co-driving. We are frightened of objects which would not have frightened us, if we ourselves had been sitting behind the wheel. The reason for this is that if we know how to drive, we see the road situation with the pedals and the wheel. Our motor-reactions not only depend ... on our perception, but our perception which in our practical life is always a pragmatic perception, equally depends upon our motor involvement. First we see how a situation is for $u s$, if we can take positive action. Anyone who after having been a passenger suddenly takes the wheel knows how the aspect of the world changes immediately. The complex of significations is completely different depending upon whether or not we sit beside the wheel or behind it.... The figure-ground relation has fundamentally changed ... An open spot in the traffic which while we were sitting beside the driver we were not or at least only with difficulty able to judge as to the possibility or impossibility of our being able to get through, we can now, that is now that we are sitting behind the wheel with our foot on the pedal, evaluate accurately and without hesitation. Thus the space and time of our world and the meaning of objects in that world depend upon the possibility we have to behave actively in that world with our entire body, and in our case with a body which has widened itself to include the car (van Lennep, 1969/1987, p. 221-22).

In the above passage we see how far van Lennep's phenomenological account deviates from the standard metaphysical account that sees car and driver as separate and distinct entities. This is not a deviation merely for the sake of deviating. Van Lennep shows - as opposed to argues - how car-driving is an embodied experience the subtleties of which cannot be adequately grasped when it is represented by a dualistic metaphysics and simplistic stimulus-response type explanations as classic behaviorist theories still believe. In the act of driving, the car becomes the driver's "instrument" taking on the condition and role of instrumentality. As instrumentality, it takes on the basic structure of the "in-order-to...." I take my car for a drive "in order to...." But now van Lennep notices a key feature of instrumentality, of instruments: In practical usage they become part of our bodies, they prolong or extend the reach of our bodies, they extend the reach of our "feel." It is in this sense that we can say that a car functions as an extension or prolongation of one's body. The driver in effect becomes the car and experiences the world in a car-like manner. Everyday speech is instructive here: When seeing an opening in busy traffic we do not say, "the car cannot get through that gap in traffic," we say, "I cannot get through that space." We are less likely to say, "the car has a flat tire," than we are to say, "I have a flat tire." The car-and-driver become one in the practical act of driving. We feel through an instrument, or more accurately still, the instrument becomes part of our body... as the blind man's cane extends the reach of his reach it prolongs his body; as the expert fisherman feels through his rod and reel the type of fish tugging at his hook he knows instantly the kind of battle he is in for. Nor should we see it as simply a case of literary hyperbole when van Lennep speaks of the driver's body "widening itself" to take in "the width of the car." When van Lennep says that the driver is "as 
wide as his car" or that his car becomes "part of his body" we should not assume he is speaking hyperbolically (i.e. figuratively). Heidegger, too, says we should not rush to take existential truths as mere metaphors, and in fact goes further in cautioning against metaphorical thinking in general. But it is time to turn back once more to my personally owned, high-mileage SUV parked on my driveway. Again, we have no desire to ignore the mundane lifeworld longer than strictly necessary.

\section{Elevating the Mundane to its Rightful Significance: Owning an Older, No-Longer-New Car and the Concern for What Matters}

Like most car owners I have my preferred shop where I take my SUV when repairs are needed or when the manual advises that scheduled maintenance is due. As the owner-driver of my SUV I try not to be neglectful. If the steering pulls left or right I schedule an inspection for a needed wheel alignment; I rotate my tires more-or-less on schedule, and install good-quality new tires whenever the old (worn) tires are no longer serviceable; I have my vehicle's brakes inspected whenever I sense the need or see a problem. All these things fall into the all-important category of mechanical safety and reliability. They are important maintenance items that cannot be left unattended. But what do we say when the so-called "problems" do not revolve around mechanical issues at all, but turn instead to things that are essentially cosmetic or perhaps even aesthetic in nature, i.e. to matters that concern the overall "appearance" or outward condition of my SUV? In what way are these things "problems" at all?

As the once-proud owner of the SUV now parked on my driveway, I cannot help but notice the deteriorating bodywork and pock-marked, age-related rust spots that are a nagging concern. Of course, for the owner-driver whose overriding concern is with newness and glossiness and up-to-date-ness in its modern innovative forms, my SUV's dented right-side fender, its misshapen rear bumper, and its badly cracked windshield will all be things that make driving a rather self-conscious, not-to-say cringe-worthy, experience. But the question nevertheless remains: Is the acceptance of aesthetic imperfection entailed in my ownership of my aging SUV an expression of materialist failing when in fact just the opposite may be true. At a minimum, it means that I am now free to take care of what matters, and what matters has little to do with the modern game of envy-arousal or the never-ending work of impression management. Such things can safely be left to the polished world of the new car showroom. What matters is that my SUV is reliable, that when I turn the key in the ignition it snaps to attention, that it drives me safely and securely to my destination. As the owner-driver, I take pride in the fact that despite its high mileage and "well-used" appearance my SUV is in mechanically sound condition. In short, what matters is that my vehicle meets the demands I place on it and takes care of the tasks I ask it to perform.

Despite its age, driving my SUV is still a pleasure. I put this down to the fact that I am familiar with its capabilities and idiosyncrasies and because time and experience have bred a degree of automaticity to my driving that makes driving easier, simpler, more routine - if never completely unconscious. A bodily connection builds between car-and-driver such that one becomes very much 'at home' in one's car: I know reflexively how much pressure needs to be applied to the brake pedal to bring my vehicle to an immediate halt - as opposed to the gradual 'push' required to bring my SUV to a gradual slow-down and eventual stop. The body learns, knows, and remembers. We have already quoted van Lennep (1969/1987) to the effect that one's car becomes a physical extension of the driver, extending the driver's reach certainly, but beyond 
that, experientially widening the driver's body to take-in the width of the vehicle he or she is driving. But this connection runs considerably deeper. We develop a certain fondness for an old car that has withstood the test of time, and time and again has brought us there-and-back safely. Memories are bundled up with this old car, connected to the inevitable trials and tribulations of motoring - a mechanical breakdown occurring miles from anywhere, a totally unexpected flat tire just ahead of an important meeting, running out of gas miles from the nearest gas station. On good days and bad my old car is more than just a mere instrumentality, more than just a manufactured thing of parts put together in a certain order to achieve a certain purpose. My car's reality resides less in its objective thing-ness than in its sentient, felt, experiential reality. At the end of the day my old car is less an assemblage of parts than an assemblage of memories — of people and places visited and tasks duly accomplished.

When the time comes to sell, trade-in, or otherwise 'let-go' of a beloved old car we run the risk of discarding something of ourselves. Are we ourselves more an assemblage of memories than of parts? Phenomenologically we might ask: Where do memories reside? Memories do not reside exclusively in $u s$. Memories exist as a silent presence running quietly along in the background of our lives, they maintain a shadow presence out there in the world, wordlessly inhabiting the world of things - in a faded photograph, in a once-heard but never quite forgotten tune or phrase of music, in an absent loved-one's fondly-remembered saying or turn-of-phrase, in the scrapes and scratches, dints and dents of an older, no-longer-new car, for example.

I feel comfortable in my SUV. Like a well-worn and well-fitting shoe, it suits my "lifestyle," assists me to run errands, takes me where I need to go, to visit family and friends, and in general to do the things I want and need to do. And as a conveying thing it adds to my life a layer of convenience and efficiency.

Still, the day is not far off when difficult decisions will have to be made. Selling, or otherwise trading in, a beloved old car is not without a certain sadness. We do not like to bring a long-running association to an end. The experience of owning or selling a new or almost brandnew car is not comparable to this, there is no bond, only an "investment." When it comes time to part ways, we may feel a sense of loss - disloyalty even that we are considering betraying an 'old friend.' We do not quite want to admit that the old car has outlived its usefulness, that its days are numbered. We weigh the "equities" and the old car comes out deficient, no longer worth maintaining in roadworthy condition. But it may also be the case that something newer, more modern, more technologically advanced has caught our eye. We do not wish to acknowledge that the rationality involved in so-called 'cost-benefit analyses' is always an emaciated rationality, there are always other equities to be weighed, there will always be something newer, something more up-to-date, more technologically advanced to catch our eye and claim our desire. There is no end to this wanting. Do we hear in this an echo of the secular prophecy of Nietzsche regarding the eternal recurrence of the same?

But today my old car is driving nicely. I complete my tasks and head for home. On the drive home I pass by the local carwash which announces in bold letters-A Clean Car Runs Better. I mull this over and decide (against all logic) that this could be right. Perhaps a clean car does run better-but this is not the type of claim that phenomenological thinking can resolve.

\section{On the Unstated "Need" for Doing Phenomenology on the Things}

The word "need" is inserted in the above heading deliberately. We are speaking in this section of the need and necessity for phenomenological thinking and we are bringing up this 
question at this point quite intentionally. We wish to ask: What is the "need" that propels us into the type of thinking we call phenomenological? Do we feel such a need? Or do we see phenomenological thinking as more "choice" than "need"? There can be little doubt that we live in a world where "choice" reigns (virtually) supreme. Does it come down to a matter of sheer personal preference, a choice of one type of research methodology over others we could - and perhaps should-have chosen? On what basis are we entitled to speak loftily of a "need" for this kind of thinking? How do we begin to go about answering such questions? Even as we close out this writing let us attempt at least a provisional response.

The pathos of phenomenology resides in the air we breathe, not so much the thoughts we think. Erudition is not the well-spring of this pathos-lived experience is. "Back to the things themselves" is the succinct expression of this. Like the asthmatic who clutches for air with every intake of breath, we too desire to breathe deeply, take in deep draughts of air, inhale and exhale deeply. We cannot make do with cramped conceptual accounts that offer little in the way of food for thought, scholarly texts that offer ontologically-depleted, theoretical accounts but nothing in the way of bodily nourishment, nothing for the soul to chew on. In his later work, Heidegger (1994) speaks disparagingly about the constant "fussing with beings" - which we can interpret as the mere ontic manipulation of what immediately presents itself - as a kind of modernist obsession. Here lies the source of the pathos of which van Manen (2019) speaks. This is not mere "verbosity" much less the "seduction by language" that Zahavi (2019) speaks of so disdainfully and in such an unbecoming manner. Instead, it is the deeply mindful response to what Heidegger would call our modern befindlichkeit - briefly, the totality of the social, historical, cultural, anthropological, epistemic, etc. circumstances in which we moderns find ourselves.

All around us the mundane life-world beckons - take another look at me, study me from top to toe, from side to side, turn me inside-out, outside-in. But in saying this we need to be aware that it is not the world's facticity that beckons, it is not facticity that arouses the felt need of which we are speaking. For that we have science and its varied and multiple offshoots. Here we are speaking of something else-something prior, something deeper. Here we are speaking of phenomenology in what van Manen (2019) calls its "originary" sense, i.e. in its non-colonized, non-hybridized, non-naturalized, non-cognitivized, non-reified form. We are emphatically not speaking of phenomenology as just another species of qualitative research. It is the world's worldliness, i.e. its inner truthfulness, that beckons. We cannot reason our way into this truthfulness - which is not to say that the task is deprived of all reason but only that something more (i.e. beyond reason) is involved. Heidegger (1994) has spoken of a "distress" that accompanies our not knowing the way out (i.e. of our current predicament), or our way in (i.e. to the inner truthfulness of the worldliness of the world). The crucial first step, as Heidegger points out, is to experience this distress, to experience this distress as something distressing. It is the experience that counts, that guides; it is the experience that is the source of the felt need of which we are speaking. Absent such experience we find ourselves engaged in admittedly erudite, but nevertheless philosophically abstract arguments, word games, wordsmithing, a concern for semantic correctness ... and so forth. This would constitute its own special brand of "verbosity."

Tasks completed I am ready to head home. On the drive home I remember to fill up my almost empty fuel tank and am taken aback by the rapidly rising price of gasoline. This is never a moment of rejoicing but with the needle now on "Full" at least I have the satisfaction of knowing that I will not need to re-fill my tank for several days, perhaps a week or more if I am careful. 


\section{References}

Gallagher, S. \& Zahavi, D. (2008). The phenomenological mind: An introduction to philosophy of mind and cognitive science. Routledge.

Heidegger, M. (1994). Basic questions of philosophy. Bloomington: Indiana University Press.

Morley, J. (2010). It's always about the epoche. Les Collectifs du Cirp, Volume 1 (edition special): 223-32.

van Lennep, D. J. (1969/1987). The psychology of driving a car. In J.J. Kockelmans, (Ed. \& Trans.), Phenomenological psychology: The Dutch School (217-27). Dordrecht, The Netherlands: Martinus Nijhoff.

van Manen, M. (2018). Rebuttal rejoinder: Present IPA for what it is-Interpretive Psychological Analysis. Qualitative Health Research, 28(12): 1959-68.

van Manen, M. (2019). Rebuttal: Doing phenomenology on the things. Qualitative Health Research, 29(1): 1-18. DOI: 10.1177/1049732319827293

Zahavi, D. (2019). The practice of phenomenology: The case of Max van Manen. Nursing Philosophy, 21(2). DOI: 10.1111/nup.12276 